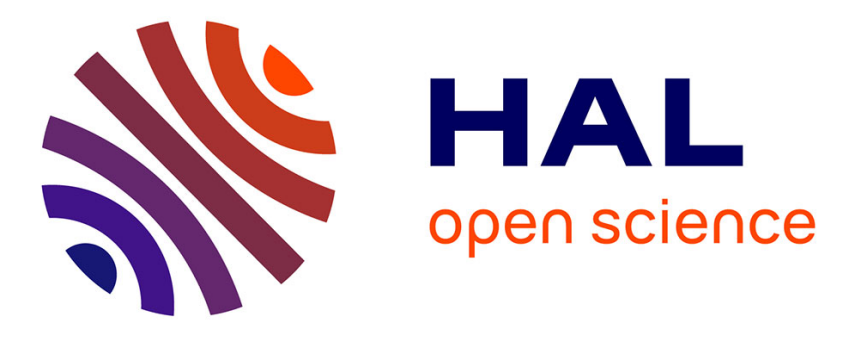

\title{
Preliminary study of ballistic impact on an industrial tank: Projectile velocity decay
}

Nicolas Lecysyn, Aurélia Dandrieux, Frederic Heymes, Pierre Slangen, Laurent Munier, Emmanuel Lapebie, Christian Le Gallic, Gilles Dusserre

\section{- To cite this version:}

Nicolas Lecysyn, Aurélia Dandrieux, Frederic Heymes, Pierre Slangen, Laurent Munier, et al.. Preliminary study of ballistic impact on an industrial tank: Projectile velocity decay. Journal of Loss Prevention in the Process Industries, 2008, 21 (6), pp.627-634. 10.1016/j.jlp.2008.06.006 . hal02012173

\section{HAL Id: hal-02012173 \\ https://hal.science/hal-02012173}

Submitted on 24 Feb 2020

HAL is a multi-disciplinary open access archive for the deposit and dissemination of scientific research documents, whether they are published or not. The documents may come from teaching and research institutions in France or abroad, or from public or private research centers.
L'archive ouverte pluridisciplinaire HAL, est destinée au dépôt et à la diffusion de documents scientifiques de niveau recherche, publiés ou non, émanant des établissements d'enseignement et de recherche français ou étrangers, des laboratoires publics ou privés. 


\title{
Preliminary study of ballistic impact on an industrial tank: Projectile velocity decay
}

\author{
Nicolas Lecysyn ${ }^{\mathrm{a}, *}$, Aurélia Dandrieux ${ }^{\mathrm{a}}$, Frédéric Heymes ${ }^{\mathrm{a}}$, Pierre Slangen ${ }^{\mathrm{a}}$, Laurent Munier ${ }^{\mathrm{b}}$, \\ Emmanuel Lapebie $^{\mathrm{b}}$, Christian Le Gallic ${ }^{\mathrm{b}}$, Gilles Dusserre ${ }^{\mathrm{a}}$ \\ ${ }^{a}$ Ecole des Mines d'Alès 6, avenue de Clavières, 30319 Alès Cedex, France \\ ${ }^{\mathrm{b}}$ Centre d'études de Gramat, Délégation Générale pour l'Armement, 46500 Gramat, France
}

\begin{abstract}
A B S T R A C T
Since the events of September 11, 2001, the possibility of an intentional act targeting the chemical process industry has become realistic. It is, therefore, a great concern to be able to predict the immediate consequences of such an act. This study is intended to improve our knowledge about the sequence of events that occurs when a high-speed bullet $\left(>1000 \mathrm{~m} \mathrm{~s}^{-1}\right)$ penetrates a vessel filled with toxic liquid. We find that, prior to liquid ejection, several well-defined phases occur, including the phenomenon known as the "hydraulic ram." This paper focuses on projectile-target interactions and explains how the decay of projectile velocity is related to the initial conditions of the target.
\end{abstract}

Keywords:

Impact

Projectile

Fluid

Vessel

Drag model

\section{Introduction}

An important concern in risk management is the effect of projectile impact on a vessel holding a toxic liquid. Such an event may occur as part of an intentional attack that targets the chemical process industry.

\subsection{Intentional act}

According to Baybutt and Ready (2003), September 9, 2001, is an important date for risk assessment in the chemical industry. Prior to this date (Bajpai \& Gupta, 2005) risk assessment focused on unintentional acts, such as human errors, technical failures, and natural calamities. Now, however, oil refineries, fertilizer plants, and petrochemical facilities are targets for terrorists. The military guide to terrorism (TRADOC, 2007) lists several weapons that could be used in intentionally destructive acts; grenades appear to be a likely possibility.

\subsection{Projectile}

According to Mott and Sneddon (1963) and Gurney (1943), who have performed tests on grenade effects (blast and

\footnotetext{
* Corresponding author. Tel.: +33 466782766; fax: +33466782701.

E-mail address: nicolas.lecysyn@ema.fr (N. Lecysyn).
}

fragmentation), the velocities of projectiles (steel or aluminium) created by fragmentation range between 1350 and $1600 \mathrm{~m} \mathrm{~s}^{-1}$. Fragments have an average mass of $0.80 \mathrm{~g}$ from grenades commonly used by terrorists (TRADOC, 2007).

Besides grenades, another way to severely damage a structure is to use a jet-shaped explosive charge. These devices provide impact velocities between 1500 and $1700 \mathrm{~m} \mathrm{~s}^{-1}$ (GlobalSecurity, 2008) with a projectile density close to that of copper (Zernow, 1997).

\subsection{Target}

According to Chamayou (1997), who has worked on storage problems in the chemical process industry, it is possible to define particular families of products that are stored in atmospheric tanks. Then a global range of physical and chemical properties of fluids can be identified, as illustrated in Fig. 1. Moreover, the same study shows us that likely targets have a characteristic dimension $H / \Phi$ (ratio of height to diameter) between $10 \%$ and $44 \%$. Thus, the characteristics of projectiles, atmospheric storage tanks, and toxic fluids are all known for those scenarios that are likely to describe an attack on a chemical process plant. This knowledge allows us to develop an experimental protocol. However, it is important to define more precisely the phenomenon to be studied. During impact on a fluid-filled tank, a high-velocity projectile forms, what specialists have called, a "hydraulic ram." 


\begin{tabular}{|c|c|c|c|}
\hline \multicolumn{2}{|c|}{ Nomenclature } & $\rho_{t}$ & target wall density $\left(\mathrm{kg} \mathrm{L}^{-1}\right)$ \\
\hline A & projectile cross-sectional area $\left(\mathrm{m}^{2}\right)$ & $s_{p}$ & Hugoniot slope coefficient of projectile material \\
\hline$C_{l}$ & sound velocity in fluid $\left(\mathrm{m} \mathrm{s}^{-1}\right)$ & & (dimensionless) \\
\hline$C_{p}$ & sound velocity in projectile material $\left(\mathrm{m} \mathrm{s}^{-1}\right)$ & $t$ & time $(s)$ \\
\hline$C_{x}$ & drag coefficient of projectile (dimensionless) & $u_{p}$ & projectile velocity after impact $\left(\mathrm{m} \mathrm{s}^{-1}\right)$ \\
\hline$\hat{d_{p}}$ & plug diameter $(\mathrm{m})$ & $u_{p 0}$ & projectile velocity before impact $\left(\mathrm{m} \mathrm{s}^{-1}\right)$ \\
\hline$m_{p}$ & mass of the projectile $(\mathrm{g})$ & $u_{p f}$ & residual projectile velocity $\left(\mathrm{m} \mathrm{s}^{-1}\right)$ \\
\hline$\mu_{l}$ & fluid viscosity (Pa s) & $u_{p 50}$ & ballistic limit which represents an impact velocity at \\
\hline $\operatorname{Re}$ & Reynolds number (dimensionless) & & which $50 \%$ of a series of identical projectiles just \\
\hline$\rho_{l}$ & fluid density $\left(\mathrm{kg} \mathrm{L}^{-1}\right)$ & & breach the target $\left(\mathrm{m} \mathrm{s}^{-1}\right)$ \\
\hline$\rho_{p}$ & projectile density $\left(\mathrm{kg} \mathrm{L}^{-1}\right)$ & $V_{p}$ & projectile volume $\left(\mathrm{m}^{3}\right)$ \\
\hline
\end{tabular}

\subsection{Hydraulic ram}

During the Apollo space project, catastrophic tank failure was studied (Stepka, Morse, \& Dengler, 1965) to understand the damage mechanism that would be induced when a meteorite impacts spacecraft fluid cells. Tests were carried out by impacting water tanks with hypervelocity projectiles (from 1301 to $6400 \mathrm{~m}$ $\mathrm{s}^{-1}$ ). In particular, researchers wanted to evaluate damage mechanisms caused by a hydraulic ram.

A hydraulic ram is a complex mechanism that involves a number of events: when a projectile enters a tank, a shock wave forms, and the high pressure and stresses near the entry point may cause cracks in the vessel. As the projectile traverses the fluid, high pressure is generated, and energy is imparted to the fluid through projectile drag. This increased energy sets the fluid in motion and forms a cavity. Fluid motion, cavity formation, and subsequent cavity collapse impose stresses on the tank walls. Finally, if the projectile has sufficient kinetic energy, it will exit the tank. As it exits, a local area of fluid is compressed, and cracks are produced around the exit hole. This phenomenon has been the subject of several investigations concerning the survivability of military aircraft fuel cells (Ball, 1976; Holm, 1973; Lundstrom \& Fung, 1976; Mueller, 1974; Townsend, Park, \& Devall, 2003). The processes involved in a hydraulic ram are summarized in Fig. 2; two steps can be identified.
1. At the time of impact there is a sudden and violent release of energy, which generates a shock wave.

2. During the time that the projectile crosses the fluid, there is an additional exchange of energy which is not as strong but of longer duration than that at impact.

This short description demonstrates the complexity of physical mechanisms that contribute to a hydraulic ram. Other laboratories have worked on the resulting liquid instabilities (Borg \& Cogar, 2007; Borg, Cogar, \& Ference, 2000; Borg, Cogar et al., 2001; Borg, Grady et al., 2001; Borg, Downs, \& Lloyd, 2006). Borg has performed a series of tests based on the same approach (projectile-target system), principally using an aluminium projectile (23.8 mm diameter) at velocities between 1630 and $6000 \mathrm{~m} \mathrm{~s}^{-1}$ impacting a steel cylinder filled with tributylphosphate (TBP). His work concerns liquid expansion and instability. Borg managed to model the mechanism of liquid expansion and subsequent breakup caused by a hydraulic ram. His theory is based on conservative laws for expansion (Gurney, 1943) and for breakup (Grady, 1988). He focused particularly on a dimensional penetration study (Borg, Cogar et al., 2001; Borg, Grady et al., 2001 ) and concluded that the phenomenon can be considered as inviscid. Moreover, he established a clear correlation between drag and liquid expansion. It is worth noting that the dimensionless ratio of projectile diameter to target diameter was $25-33 \%$. In

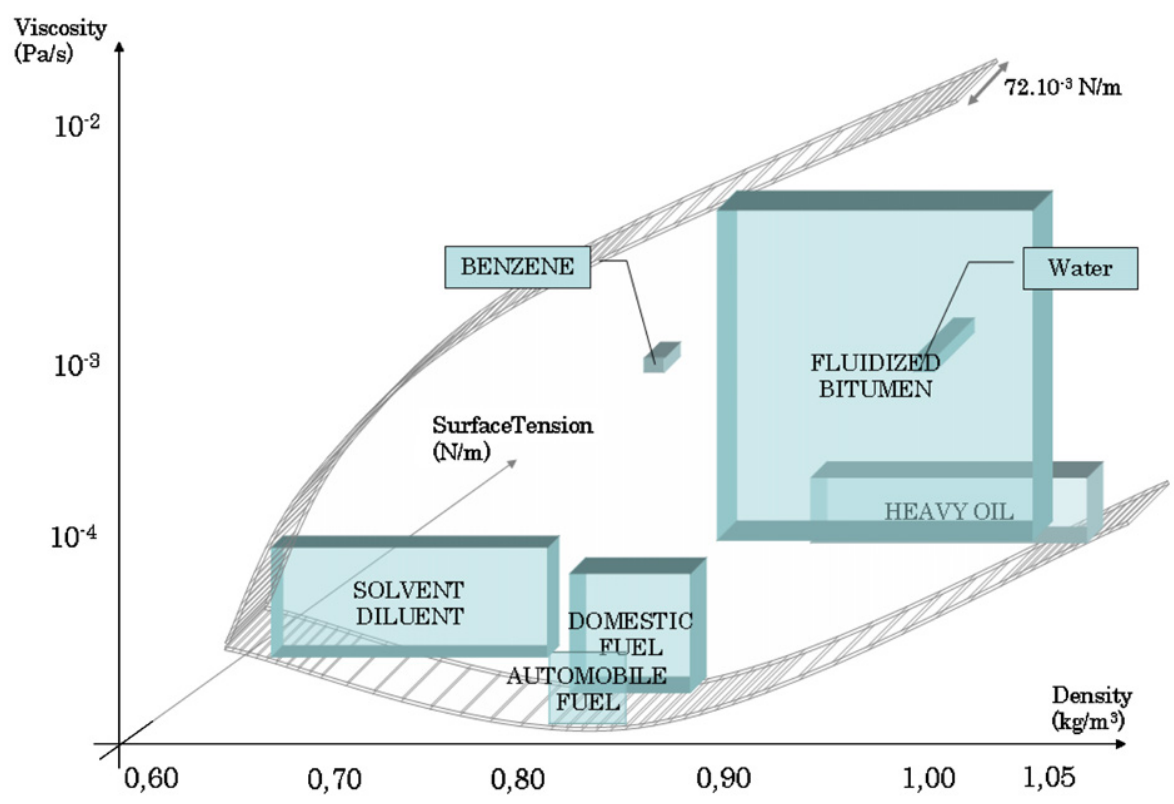

Fig. 1. Synthesis of liquids properties stored in atmospheric tanks. 
this case the penetrating projectile was clearly the source of fluid ejection, as described in Fig. 3.

\subsection{Objectives}

The aim of our work is to continue such studies, focusing on volatile toxic liquids, which are expected to be targets of an intentional act. Full-scale tests were recently carried out at the Centre d'Etudes de Gramat (CEG) to assess the consequences of an impact on a tank filled with an industrial liquid. The first aim of this project was to study the hydraulic ram; in particular, to study the drag and cavitation phases. An original feature of our approach is that losses in projectile energy were determined without having sensors in the fluid. Another feature is that dimensionless ratios of projectile to target diameters were less than $2 \%$; this is a medium value compared to laboratory experiments (25-33\% in Borg \& Cogar, 2007; Borg, Cogar, \& Ference, 2000; Borg, Cogar et al., 2001; Borg, Grady et al., 2001; Borg, Downs, \& Lloyd, 2006) and largescale tests $(0.003 \%$ average ratio between an explosive-device fragment and an atmospheric tank).

In this paper, we report

- measurements of the movement and deceleration of a projectile after it impacts a fluid-filled vessel, and

- compare the subsequent velocity decay to a hydrodynamic model.

The analysis leads us to propose an analytic model that relates the drag phase of a hydraulic ram to the physical and chemical properties of the stored fluid. This first step is expected to

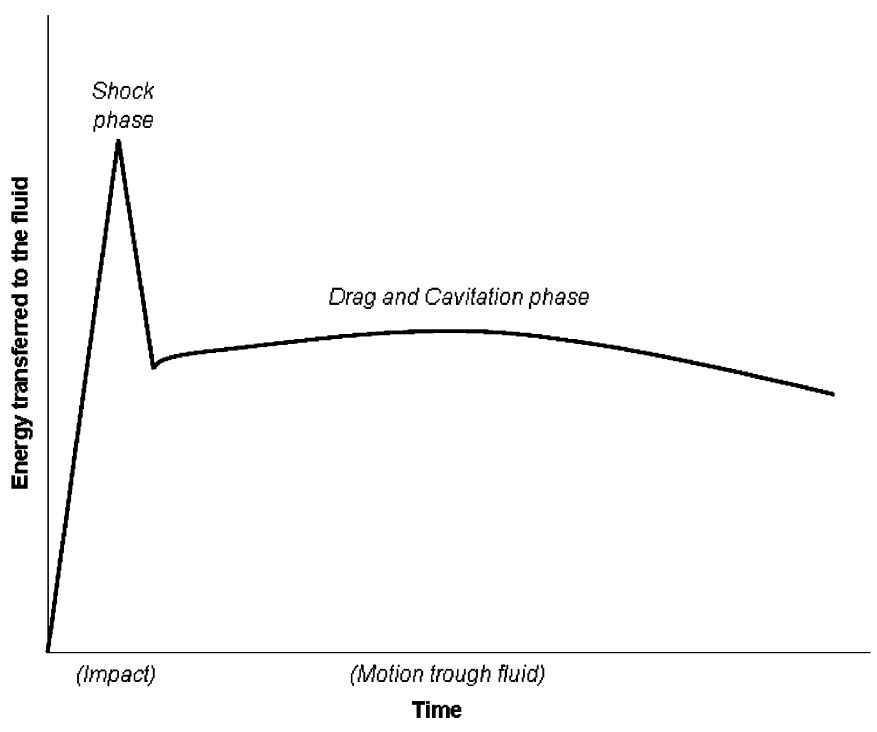

Fig. 2. Proposed outline of hydraulic ram, adapted from Holm (1973). highlight fundamental parameters that can be used to establish a complete model for flow and breakup.

\section{Apparatus and methods}

\subsection{Introduction}

Tests were performed to reproduce a projectile impacting a liquid-filled tank. A gun was used to accelerate a sabot device containing a small spherical projectile. To measure liquid fragmentation and subsequent evaporation, two devices were set up:

- a very high-speed frame recording device $(4000 \mathrm{~Hz})$, and

- a chemical-sensor mesh $(1 \mathrm{~Hz})$.

In this paper, chemical sensors do not play a role because only the first milliseconds of the phenomena are analysed; therefore, the chemical-sensor mesh is not described here.

\subsection{Test vessels}

The experimental setup is presented in Fig. 4. A cylindrical steel vessel (diameter $=360 \mathrm{~mm}$, height $=622 \mathrm{~mm}$, volume $=60 \mathrm{~L}$, thickness $=0.7 \mathrm{~mm}$ ) was slightly attached to two poles, spaced at contact points between the vessel and two neighbouring pseudovessels. To be representative of industrial storage, the liquid vessel was not completely filled (height of gas phase $=40 \mathrm{~mm}$ ).

Vessels were commercial $60 \mathrm{~L}$ capacity barrels (Manutan). They were manufactured from steel of thickness $1 \mathrm{~mm}$ for the plane parts and thickness $0.6 \mathrm{~mm}$ for the side cylinders. The real volume of each barrel was about $63 \mathrm{~L}$ (Fig. 5). Consequently, the dimensionless ratio of projectile to target diameter was less than $2 \%$.

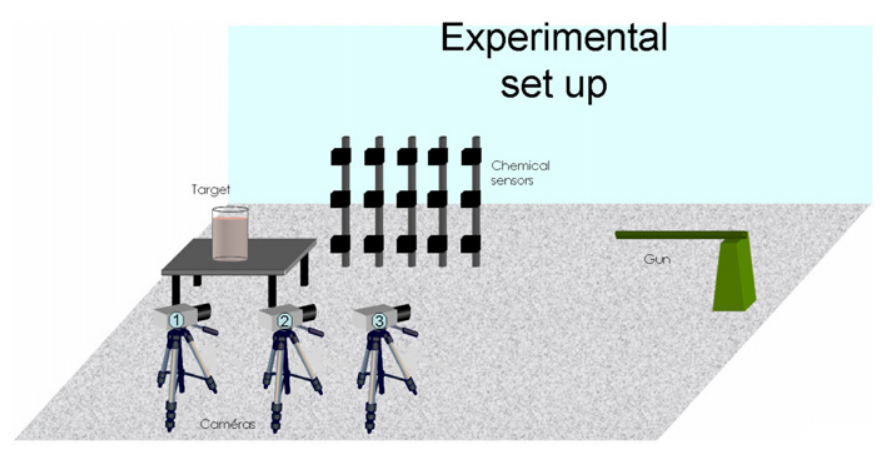

Fig. 4. Experimental setup.
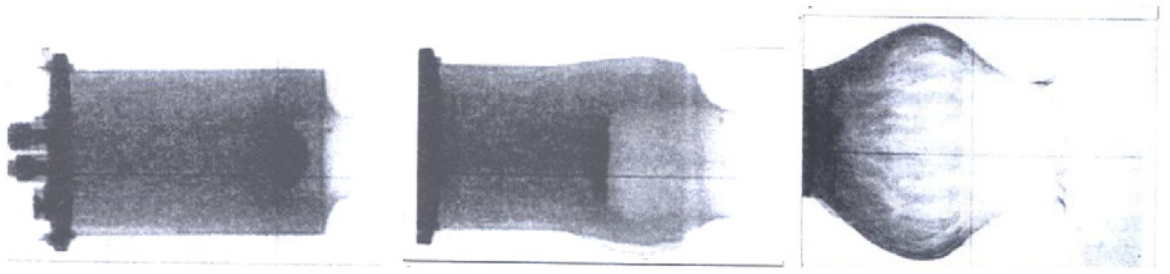

Fig. 3. Liquid expansion during projectile penetration, from Borg, Grady et al. (2001). 


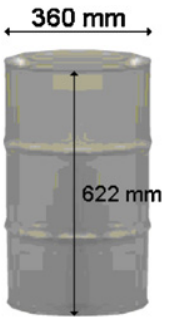

Fig. 5. Target vessel.

\subsection{Solution properties}

Two types of solutions were used in the experiments. Each contained urban water either with or without polyethylene glycol 400. Polyethylene glycol 400 is a liquid at ambient temperature and is a polymer characterized by a high viscosity. Binary mixtures (containing either $40 \%$ or $74 \%$ PEG mass fraction) are representative of common organic liquids that are stored in the chemical process industry (see Fig. 1 ); for example, crude oil has a viscosity of about 4 Pas. The physico-chemical characteristics of the solutions are expected to influence the system's response to impact events.

Densities $\rho\left(\mathrm{kg} \mathrm{L}^{-1}\right)$ of aqueous solution of polyethylene glycol 400 are given in the literature (Yurquina, Manzur, Brito, Manzo, \& Molina, 2007; Kirincic \& Klofutar, 1999). Thus, the properties of the aqueous solutions employed in these tests are located in the middle right part of Fig. 1.

\subsection{Projectiles}

The projectiles used for the impact tests were solid spheres whose diameters were assumed constant even after impact $(13 \mathrm{~mm})$. The projectile material was Denal, which is a tungsten alloy; the particle mass ranged from 20.1 to $20.2 \mathrm{~g}$. Each bullet was fired at a distance of $15 \mathrm{~m}$ from the vessel.

For those tests involving projectiles of diameters smaller than that of the launch tube bore, it was necessary to use a sabot that held the projectile during its travel through the launch tube. After exiting the launch tube, the sabot separates from the projectile and departs from the projectile flight path, so only the projectile impacts the target tank.

\subsection{Optical apparatus}

A high-speed framing technique has previously been applied to hydrodynamic studies of, for example, diesel jet breakup (Chigier, 1991), water spray (Amielh, Giorgetti, Heichelbech, \& Tchiftchibachian, 2006), water entry and supercavitation (Holm, 1973; Shi, Motoyuki, \& Takuya, 2000). In those studies the scene was illuminated by a background light, which was scattered by the jet. In our experiment, because of specific conditions due to the gun, the target was illuminated directly with three spotlights of $3500 \mathrm{~W}$ each. However, natural sunshine was the major source of light so, from one test to another, optical conditions were not the same. The field of view of each camera was within $2.5 \mathrm{~m}$ and the focal distance was chosen to provide complete coverage of the experimental field. Optical aberrations are estimated to be $2 \%$ of maximum full field. The use of a supersensitive 10 bit complementary metal oxide semi-conductor (CMOS) was chosen for its ability to capture fast events (Schmitt, Hugenschmidt, \& Baca, 2004). The cameras were Photron Fast Cam APX 120K, working at 4000 frames per second at full resolution $(1024 \times 1024$ pixels $)$. Video sequences were processed to enhance the projectile displacement images (Lecysyn, Heymes, Dandrieux, Slangen, Dussere, Munier, Lapebie, \& Le Gallic, 2007); postprocessing consisted of filtering, eroding, and thresholding of each image from the shotgun sequences.

\subsection{Projectile velocity measurement}

The exposure time (equal to the frame recording rate) of the camera was long enough (compared to bullet time of flight) to record an "optical smear" (Fig. 6). This optical smear was highlighted on images from camera \#1. The "optical smear" length divided by the exposure time $(1 / 4000 \mathrm{~s})$ provides projectile velocities. Accuracy depends (a) on optical aberrations, which were of $2 \%$, and (b) on camera calibration ( $3 \mathrm{~mm}$ per pixel), which gave an error of $12 \mathrm{~m} \mathrm{~s}^{-1}$; therefore, the projectile velocities were measured with an accuracy of $0.8-1.8 \%$.

As a result, it was possible to measure projectile velocities both before and after impact; this allowed us to obtain values for the velocity decay in the vessel. It is important to note that projectile velocity was not measured in the liquid. Indeed, the average velocity values were obtained from projectiles in air, where energy loss due to drag is insignificant compared to that in the liquid system (at least, over the very short time intervals studied here). This is why experimental values from this optical technique are assumed to be the initial and final velocities of the projectile in the target.

\section{Results and discussion}

\subsection{Description of the phenomenon}

From the video recordings of each shot, we can obtain an empirical description of the observed phenomenon. The recordings show that catastrophic tank failure can be divided into the following sequence of events (see Fig. 7):

(a) Phase 0 in which the projectile impacts and penetrates the vessel (less than $0.5 \mathrm{~ms}$ ),

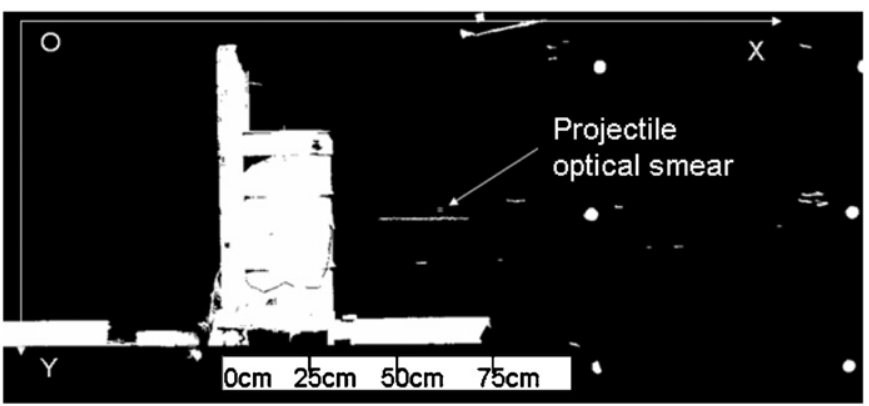

Projectile before impact

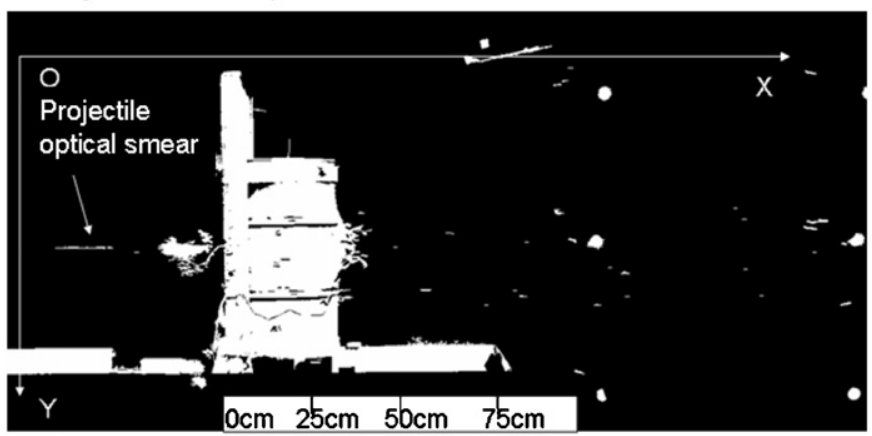

Projectile after impact

Fig. 6. Optical measurement of projectile velocity. 
(b) Phase 1 in which a liquid jet (snake-tongue geometry) is ejected (less than $30 \mathrm{~ms}$ ),

(c) Phase 2 in which the liquid breaks up, ligaments form, and drops coalescence with lower velocities than in phase 1 (about $250 \mathrm{~ms}$ ),

(d) Phase 3 in which there is gravity flow of the liquid through the failure hole (a few tens of seconds).

Vaporization is a fourth phase, which is expected to begin during phase 2 and to continue for a 5 min thereafter. It would be of interest to discuss each of these phases; however, the goal of this study is to identify static and dynamic parameters that can be used to correlate liquid ejection, breakup, and vaporization. Therefore, in this paper we focus on energy input during the initial phase.

\subsection{Projectile velocity experimental values}

Six gunshots (Table 1) gave projectile speeds in the range $850-1250 \mathrm{~m} / \mathrm{s}$ at impact on the vessel. Each projectile was fired into the centre of the vessel. Because of the ratio between target and projectile diameters, it is assumed that any uncertainties due to shot misalignment are negligible. Each video sequence was processed to obtain the optical smear length both before and after impact. The resulting values for projectile velocity loss in the target vessel are listed in Table 1 for each shot.

Velocity loss varied from $30 \%$ to $40 \%$, depending on experimental conditions. However, there is no clear correlation between velocity loss and either mixture viscosities or densities. A dimensional analysis is proposed in Section 3.6 to get sensitive parameters that can explain the liquid system response to impact.

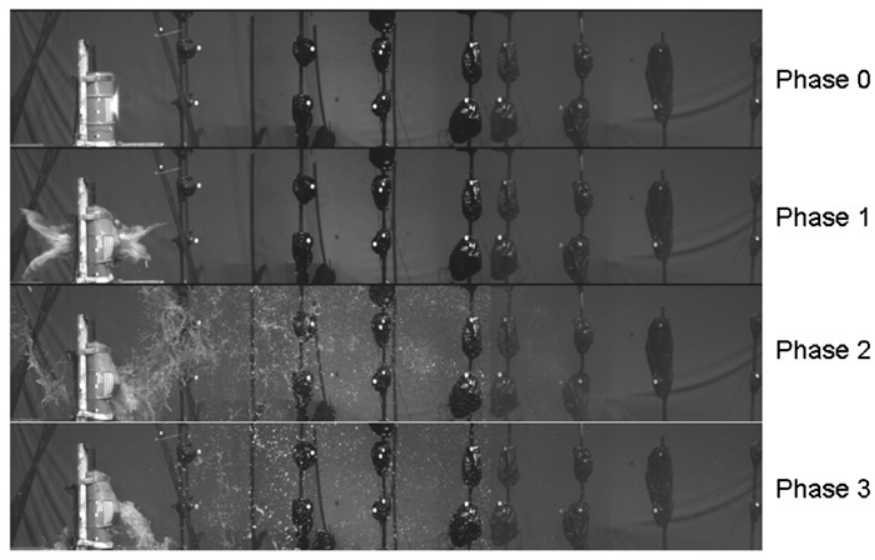

Fig. 7. Different phases of liquid discharge.

Table 1

Experimental values for CEG tests series

\begin{tabular}{lllllll}
\hline $\begin{array}{l}\text { Shot } \\
\text { no. }\end{array}$ & $\begin{array}{l}u_{p 0} \\
\left(\mathrm{~m} \mathrm{~s}^{-1}\right)\end{array}$ & $\begin{array}{l}u_{p} \\
\left(\mathrm{~m} \mathrm{~s}^{-1}\right)\end{array}$ & $\begin{array}{l}\text { Velocity } \\
\text { loss }(\%)\end{array}$ & $\begin{array}{l}\text { PEG 400 } \\
(\text { mass \%) }\end{array}$ & $\mu_{l}$ (Pa s) & $\begin{array}{l}\rho_{l} \\
\left(\mathrm{~kg} \mathrm{~L}^{-1}\right)\end{array}$ \\
\hline 1 & 1192 & 731 & 39 & 0 & 0.176 & 0.950 \\
2 & 1472 & 881 & 40 & 0 & 0.176 & 0.950 \\
3 & 1003 & 680 & 32 & 40 & 4.83 & 1.065 \\
4 & 1235 & 816 & 34 & 40 & 4.83 & 1.065 \\
5 & 1042 & 645 & 38 & 74 & 23.66 & 1.077 \\
6 & 1044 & 650 & 38 & 74 & 23.66 & 1.077 \\
\hline
\end{tabular}

\subsection{Modelling decay of projectile velocity after impact}

The decay ratio of projectile velocity after impact is plotted in Fig. 8. A drag Eq. (1) has been used, assuming that the projectile remained intact and did not deform,

$\rho_{p} V_{p} \frac{\mathrm{d} u_{p}}{\mathrm{~d} t}=-\frac{1}{2} C_{x} \rho_{l} A u_{p}^{2}$

Two different methods have been used to solve Eq. (1).

In the first method, we integrate (1), assuming $C_{x}$ is constant (Stepka et al., 1965). The result is

$u_{p}(t)=\frac{u_{p 0}}{1+\frac{3}{4} C_{x}\left(\rho_{l} u_{p 0} / \rho_{p} d_{p}\right) t}$

The term $C_{x}\left(\rho_{l} u_{p 0} / \rho_{p} d_{p}\right) t$ is an interesting dimensionless combination of experimental parameters; it is used in Section 3.5.

In the second method, we solve the differential equation (1) numerically, like Borg et al. (2000), but using Euler's method. From the projectile velocity at time $t$, we estimate a new value at $(t+\Delta t)$ by

$u_{p}(t+\mathrm{d} t)=u_{p}(t)-\frac{\rho_{\text {fluid }} A C_{x}\left(u_{p}\right) u_{p}(t)^{2}}{2 m_{p}} \Delta t$

Values for $C_{x}$ were determined as functions of the Reynolds number, according to the Brauer relation (Midoux, 1993):

$C_{x}=\frac{24}{\operatorname{Re}}+\frac{3.73}{\sqrt{R e}}-\frac{4.83 \times 10^{-3} \sqrt{R e}}{1+3 \times 10^{-6} R e^{3 / 2}}+0.49$

\subsection{Effect of impact into the fluid}

In both methods for predicting the projectile velocity through the vessel, it was assumed that the bullet punctured the tank wall. To model the instantaneous velocity decay due to impact, the Hugoniot-Rankine (Borg et al., 2000) relation (5) was added to (3).

$\rho_{p} C_{p}\left(u_{p 0}-u_{p}\right)+\rho_{p} s_{p}\left(u_{p 0}-u_{p}\right)^{2}=\rho_{l} C_{l} u_{p 0}+\rho_{l} s_{l} u_{p 0}^{2}$

This is a one-dimensional model based on conservative laws applied when a gas, initially at rest, is shocked by a piston. In our experiments, the target is a thin wall $(0.7 \mathrm{~mm})$ of steel, hit by a very dense projectile that is assumed to be nondeformable. That is why it is assumed that the steel wall does not have any influence on the velocity decay.

Eq. (5) is a quadratic polynomial in the variable $\left(u_{p 0}-u_{p}\right)$. For a spherical projectile made of Tungsten impacting a waterfilled tank, Fig. 8 shows solutions of (5), expressed as the ratio $\left(u_{p 1} / u_{p 0}\right)$, for velocities in the range $\left[1000,1500 \mathrm{~m} \mathrm{~s}^{-1}\right]$. The velocity decay varies from $5.1 \%$ to $6.4 \%$. This model is used in the next section for comparison with the hydrodynamic model given by (2).

\subsection{Comparison between experiment and theory}

Our experimental results are compared in Table 2 with those from the above models. The results from (2) (with constant $C_{x}$ ) are very similar to those obtained from (3) to (5) (with varying $C_{x}$ ); the differences are less than $5 \%$. This slight discrepancy could be explained by the predicted loss of velocity due to impact, as described in Section 3.4. This agreement suggests that taking into account only drag is enough to explain the velocity loss of the projectile. Note that these projectile velocities are less than $C_{l}$, the speed of sound in the liquid.

To identify sensitive parameters that can explain the system's response to impact, we chose the drag model from Stepka et al. 


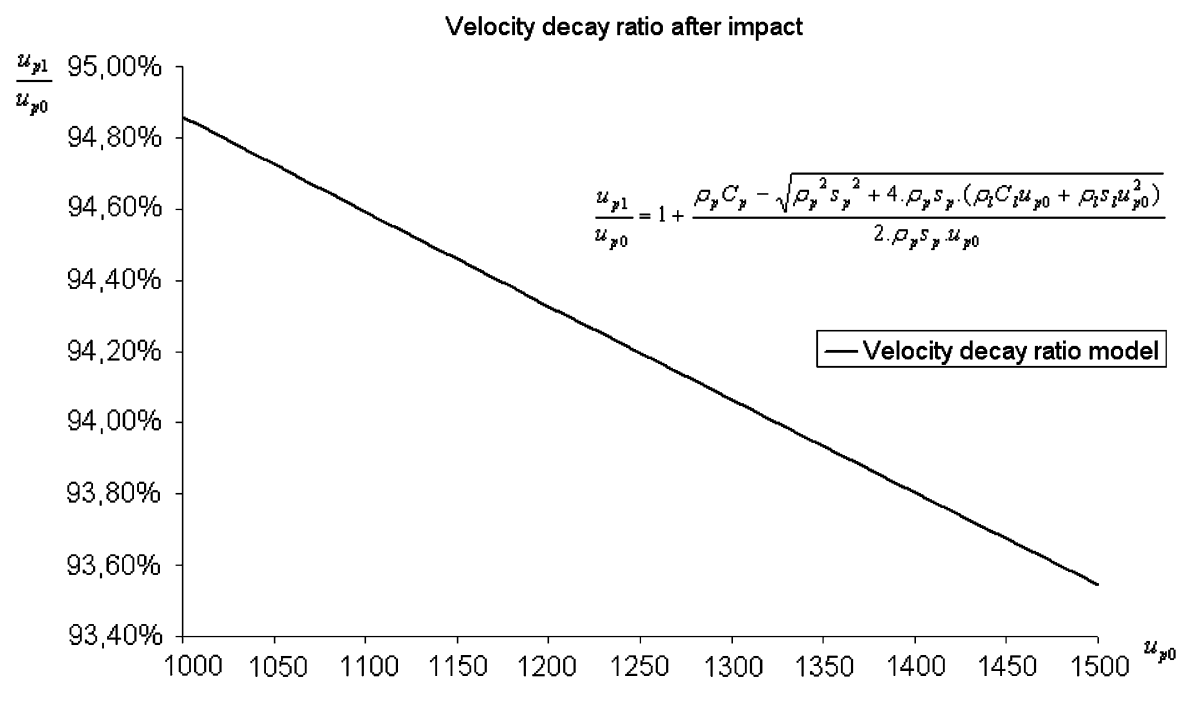

Fig. 8. Velocity decay of a projectile after impact.

Table 2

Experimental and predicted values

\begin{tabular}{|c|c|c|c|c|c|}
\hline \multirow[t]{2}{*}{$\begin{array}{l}\text { Shot } \\
\text { no. }\end{array}$} & \multicolumn{2}{|c|}{ Experimental values } & \multicolumn{2}{|c|}{$\begin{array}{l}\text { Predicted velocities after } \\
\text { impact }\left(\mathrm{m} \mathrm{s}^{-1}\right)\end{array}$} & \multirow{2}{*}{$\begin{array}{l}\text { Impact } \\
\text { paramete }\end{array}$} \\
\hline & $\begin{array}{l}\left(u_{p} / u_{0}\right) \\
(\%)\end{array}$ & $\begin{array}{l}u_{\mathrm{p}} \\
\left(\mathrm{m} \mathrm{s}^{-1}\right)\end{array}$ & $\begin{array}{l}\text { Constant } \\
C_{x}^{a}\end{array}$ & $\begin{array}{l}\text { Nonconstant } \\
C_{x}{ }^{b}\end{array}$ & \\
\hline 1 & 61 & 731 & 748 & 742 & 0.90 \\
\hline 2 & 60 & 881 & 891 & 883 & 0.91 \\
\hline 3 & 68 & 680 & 667 & 648 & 0.66 \\
\hline 4 & 66 & 816 & 821 & 800 & 0.75 \\
\hline 5 & 62 & 645 & 674 & 642 & 0.64 \\
\hline 6 & 62 & 650 & 675 & 643 & 0.64 \\
\hline
\end{tabular}

a Stepka et al. (1965).

b With Hugoniot-Rankine (Borg et al., 2000).

(1965). These dimensionless parameters are identified:

Impact parameter $=\frac{C_{x} \rho_{l} u_{p 0}}{\rho_{p} d_{p}} t$

and

Velocity decay $=\frac{u_{p}}{u_{p 0}}$

Experimental points from the studies of Stepka et al. (1965) are plotted with our data in Fig. 9. To get a suitable comparison, experimental values taken before and after the projectile penetrates the target have been considered to be the same as those entering and exiting the liquid (modifying $t$ term, assuming the loss of velocity in air is not significant).

These experimental values and those from the models, for impact parameters in the range of those in the tests by Lecysyn et al. (2007), confirm that the velocity decay is between $30 \%$ and 40\%. Moreover, Fig. 9 shows an inverse relation between projectile deceleration and impact parameter. This confirms that mixture properties are not enough to explain the liquid system's response to impact. To cover the entire range of liquid properties described in Fig. 1, more experiments must be performed with other liquids.

Discrepancies between the Stepka et al. (1965) experimental values and the drag-model predictions could be explained by discrepancies in the ranges of velocities; in the Stepka et al. (1965) tests, the projectile was supersonic in the liquid. Such high velocities are beyond the range of validity of (2).

However, the two points corresponding to shots into a 74\% PEG 400 mass-fraction solution do not agree well with the model. Fig. 10 shows that the composition of an aqueous solution affects the Reynolds number of the wake of a projectile, but composition does not affect $C_{x}$ values. This observation agrees with the Borg et al. (2000) dimensional analysis, which relates viscosity to projectile penetration.

\subsection{Effect of impact onto target walls}

As described by Holm (1973), when a tank is hit by a highvelocity projectile, dynamic stresses are generated and transmitted through the wall. These stresses are caused by the puncturing and cratering action resulting from the projectile's impact; they take the form of compressive and circumferential bending stresses in the wall. As the projectile penetrates the liquid, drag pressure and cavity formation contribute to local fluid compression near the rear wall; this compression causes cracks in the tank walls. Thus, only the penetrating action into the front wall is expected to slow down the projectile. As described by Morse and Stepka (1966) for a given projectile material, fractures of tank walls occur at lower impact kinetic energies for smaller diameter projectiles. Perhaps this can be explained by an impedance transfer mechanism, which is assumed to be promoted by two factors: high velocity of sound for the material and a small-dimension projectile, which better propagates acoustic shock waves. In any case, the hydrodynamic model (2) predicts values that agree with the experimental ones; therefore, we neglected wall-projectile interactions. Such interactions will be more important in studies of fracture mechanisms.

\section{Conclusions}

Tests were performed to analyse the consequences of highspeed impacts of projectiles onto a tank filled with a toxic liquid. Such an impact results in catastrophic failure of the vessel and leads to liquid fragmentation within $250 \mathrm{~ms}$ of impact. In this study, we measured and modelled the decay of projectile velocity 


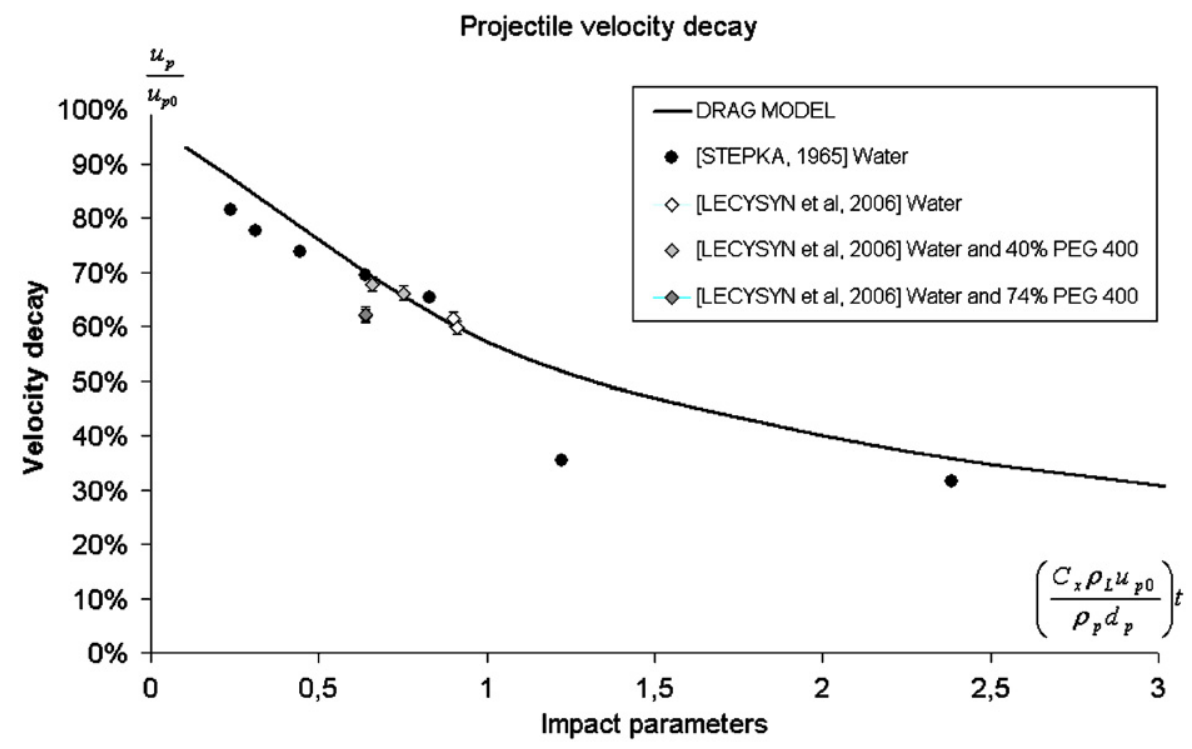

Fig. 9. Velocity decay in the fluid.

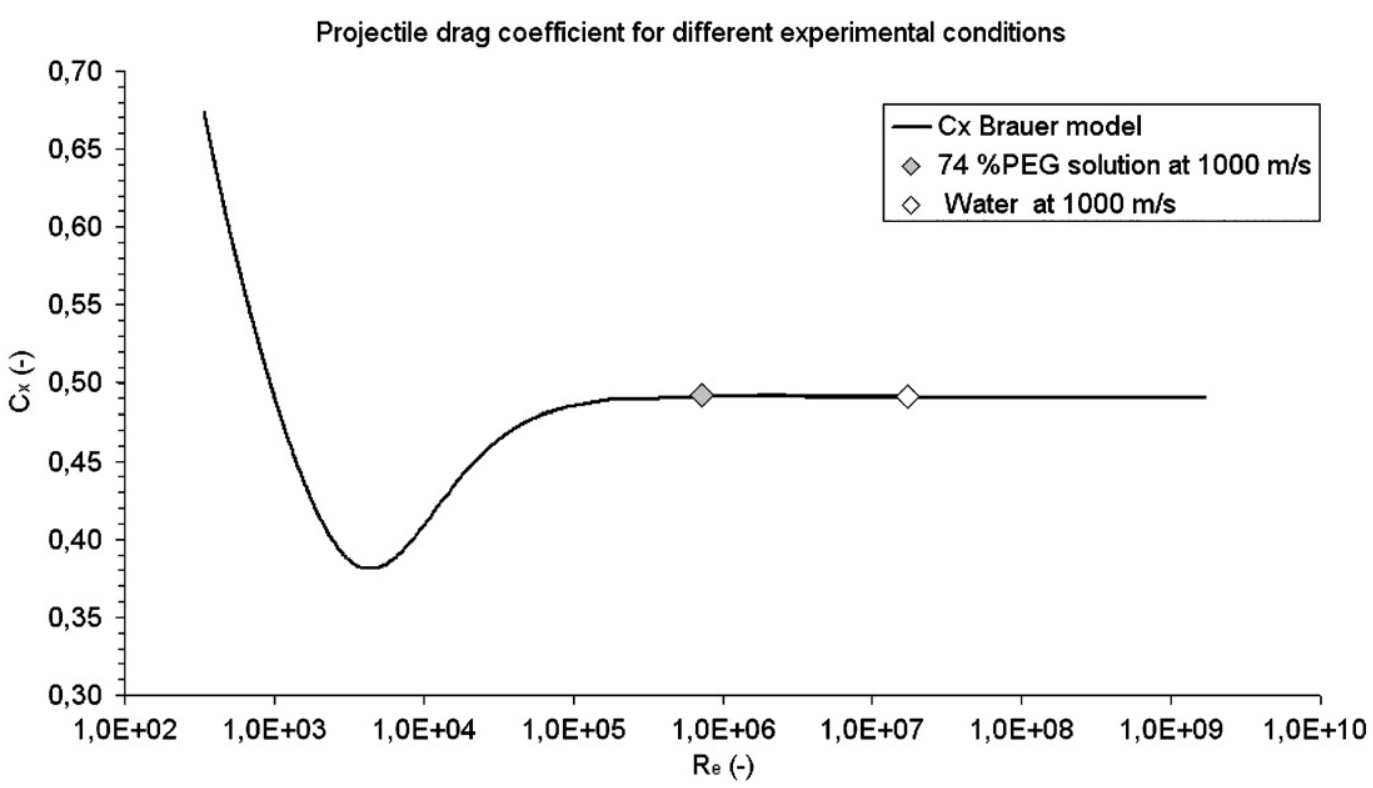

Fig. 10. $C_{x}$ values as a function of Re.

as it passed through the liquid. Projectile velocities were measured from sequences of processed images. The results suggest that projectile penetration is not sensitive to liquid density or to liquid viscosity (high drag coefficient). A dimensional analysis was proposed to improve our understanding of the impact phenomena. To model projectile velocity decay, a drag equation was solved in two ways: one assuming the drag coefficient was constant, the other assuming it depends on the projectile velocity. The two approaches produced very similar results.

The energy loss on impact with the vessel was taken into account by appealing to Hugoniot-Rankine relations; however, the resulting energy losses were found to be negligible. The velocity-decay model agrees well with experimental data, implying that any loss of kinetic energy during impact is totally dissipated into the liquid. Dimensional analysis shows that the projectile velocity decreases from $30 \%$ to $40 \%$, depending on impact parameters.
This analysis constitutes an important step toward understanding projectile-target interactions during certain industrial accidents. In the next step, we intend to characterize liquid discharge, the fragmentation mechanism, and the consequent evaporation. The ultimate goal of this project is to obtain an integrated description from projectile impact to consequences in terms of container failure, catastrophic liquid discharge, and final breakup, which would lead to evaporation and atmospheric dispersion (cloud concentrations).

\section{References}

Amielh, M., Giorgetti, J.-D., Heichelbech, J.-P., \& Tchiftchibachian, A. (2006). Granulométrie et vélocimétrie de l'atomisation primaire d'un jet liquide par analyse d'image. 10ème Congrès Francophone de Techniques Laser, 19-22 septembre, 2006, Toulouse, France.

Bajpai, S., \& Gupta, J. P. (2005). Site security for chemical process industry. Journal of Loss Prevention in the Process Industries, 18(4-6), 301-309. 
Ball, R. E. (1976). Structural response of fluid-containing-tank to penetrating projectiles (Hydraulic ram)—A comparison of experimental and analytical results. NPS-57Bp76051 (105pp.).

Baybutt, P., \& Ready, V. (2003). Strategies for protecting process plants against terrorism, sabotage and other criminal acts. Primatech Inc.

Borg, J. P., \& Cogar, J. R. (2007). Comparison of average radial expansion velocity from impacted liquid filled cylinders. International Journal of Impact Engineering, 34, 1020.

Borg, J. P., Cogar, J. R., \& Ference, S. L. (2000). Dimensionless analysis of fluid dispersion from a thin-walled container impacted by a spherical projectile. Emerging Technologies in Fluids, New York, PVP-VOL 414-1, 263-270.

Borg, J. P., Cogar, J. R., Tredways, S., Yagla, J., \& Zwiener, M. (2001). Damage resulting from high speed projectile liquid filled metal tanks. In Computational methods and experimental measurements, Vol. X (pp. 889-902). Wassex Institute of Technologies Press.

Borg, J. P., Downs, T. J., \& Lloyd, A. (2006). High strain rate fragmentation of liquid systems at atmospheric pressure. International Journal of Impact Engineering, 33, 119.

Borg, J. P., Grady, D., \& Cogar, J. R. (2001). Instability and fragmentation of expanding liquid systems. International Journal of Impact Engineering, 26, 65-76.

Chamayou, R. (1997). Techniques de l'ingénieur. Génie mécanique BM 6592.

Chigier, N. (1991). Optical imaging of sprays. Progress in Energy and Combustion Science, 17, 211-262.

GlobalSecurity. <http://www.globalsecurity.org/military/systems/munitions/bullets2warheads.htm $\rangle$; Accessed in April 2008.

Grady, D. E. (1988). The spall strength of condensed matter. Journal of the Mechanics and Physics of Solids, 36(3), 353.

Gurney, R. W. (1943). The initial velocities of fragments from bombs, shells and grenades. BRL report 405.

Holm, P. D. (1973). Hydraulic ram shock wave and cavitation effects on aircraft fuel cell survivability (p. 80).

Kirincic, S., \& Klofutar, C. (1999). Viscosity of aqueous solutions of poly(ethylene glycol)s at 298.15 K. Fluid Phase Equilibria, 155, 311.
Lecysyn, N., Heymes, F., Dandrieux, A., Slangen, P., Dusserre, G., Munier, L., Lapebie E., \& Le Gallic, C. (2007). Experimental investigation of a catastrophic tank failure with a high speed video recorder. Image processing and hydrodynamic characterization of the liquid jet. In 12th international symposium on loss prevention and safety promotion in the process industries, Edinburgh, Scotland Topic 4, Paper 212.

Lundstrom, E. A., \& Fung, W. K. (1976). Fluid dynamic analysis of hydraulic ram III (Result of analysis). JTCG/AS-74-T-015 (136pp.).

Midoux, N. (1993). Mécanique et Rhéologie des fluides en génie chimique, $3^{\text {ème }}$ tirage (p. 512).

Morse, C. R., \& Stepka, F. S. (1966). Effects of projectile size, material, and impact velocity on metal wall fracture of liquid filled tank. NASA-TN-D-3627 (p. 17).

Mott, N. F., \& Sneddon, I. N. (1963). Wave mechanics and its applications. New York: Dover Publications.

Mueller, L. S. (1974). Experimental investigation of hydraulic ram.

Schmitt, R., Hugenschmidt, M., \& Baca, W. (2004). Kurzzeitkinematographie mit digitaler Kameratechik Technologie des caméras numériques utilisée en cinématographie ultrarapide. ISL, PU618/2004 (p. 10).

Shi, H. H., Motoyuki, I., \& Takuya, T. (2000). Optical observation of the supercavitation induced by high-speed water entry. Transactions of the ASME, $122,806-810$.

Stepka, F. S., Morse, C. R., \& Dengler, R. P. (1965). Investigation of characteristics of pressure waves generated in water filled tanks impacted by high-velocity projectiles. TN D-3143 (p. 22)

Townsend, D., Park, N., \& Devall, P. M. (2003). Failure of fluid filled structures due to high velocity fragment impact. International Journal of Impact Engineering, 29 723-733.

TRADOC. (2007). US army training and doctrine command, TRADOC G2 TRADOC intelligence support activity-Threats. Military Guide to Terrorism in the Twenty-First Century. White Paper, Version 5.0.

Yurquina, A. Manzur, M. E. Brito, P. Manzo, R., \& Molina, M. A. A (2007) Physicochemical studies of acetaminophen in Water-Peg 400 systems. Journal of Molecular Liquids, 133, 47.

Zernow, L. (1997). The density deficit in stretching shaped charge jets. International Journal of Impact Engineering, 20(6-10), 849-860. 